\title{
Review Article \\ Ecological Complexity and the Success of Fungal Biological Control Agents
}

\author{
Guy R. Knudsen ${ }^{1}$ and Louise-Marie C. Dandurand ${ }^{2}$ \\ ${ }^{1}$ Soil \& Land Resources Division, University of Idaho, Moscow, ID 83844, USA \\ ${ }^{2}$ Department of Plant, Soil, \& Entomological Sciences, University of Idaho, Moscow, ID 83844, USA \\ Correspondence should be addressed to Guy R. Knudsen; gknudsen@uidaho.edu
}

Received 5 February 2014; Revised 29 April 2014; Accepted 30 April 2014; Published 1 June 2014

Academic Editor: Tibor Janda

Copyright (c) 2014 G. R. Knudsen and L.-M. C. Dandurand. This is an open access article distributed under the Creative Commons Attribution License, which permits unrestricted use, distribution, and reproduction in any medium, provided the original work is properly cited.

\begin{abstract}
Fungal biological control agents against plant pathogens, especially those in soil, operate within physically, biologically, and spatially complex systems by means of a variety of trophic and nontrophic interspecific interactions. However, the biocontrol agents themselves are also subject to the same types of interactions, which may reduce or in some cases enhance their efficacy against target plant pathogens. Characterization of these ecologically complex systems is challenging, but a number of tools are available to help unravel this complexity. Several of these tools are described here, including the use of molecular biology to generate biocontrol agents with useful marker genes and then to quantify these agents in natural systems, epifluorescence and confocal laser scanning microscopy to observe their presence and activity in situ, and spatial statistics and computer simulation modeling to evaluate and predict these activities in heterogeneous soil habitats.
\end{abstract}

\section{Introduction}

Reduction of chemical pesticide usage, including chemicals for control of soilborne plant pathogens, is widely recognized as a desirable goal for agriculture and forestry. Many traditional chemical means of disease control (e.g., methyl bromide and certain fungicides) are being or have been phased out due to economic considerations and/or mandate. Application of fungi and bacteria as microbial antagonists of plant pathogens offers prospects of environmentally benign pest control. A wide range of fungi have shown potential as agents for biological control of soilborne phytopathogens, and this review will focus on these fungal biocontrol agents.

Unlike gnotobiotic systems, soil is characterized by a multitude of both trophic (food webs) and nontrophic (e.g., mutualism, commensalism, neutralism, amensalism, antagonism, and competition) interspecific relationships [1]. The distinction between trophic and nontrophic relationships is somewhat arbitrary, since it focuses only on "what an organism eats and what eats it." Parasitism typically is categorized as a trophic interaction, since a parasite derives nutrition from its host, whereas mutualism is generally considered a nontrophic interaction. Nonetheless, in an alternate taxonomy of interspecific relationships, mutualism and parasitism are often considered to be part of a continuum $[2,3]$.

Biocontrol microbes that are applied to seeds or soil prior to planting may colonize the spermosphere and/or rhizosphere of seedlings and thus may be present at or near infection courts of soilborne pathogens. There, biocontrol agents may participate in a variety of trophic and nontrophic interaction mechanisms including production of antifungal compounds, hyperparasitism of pathogens, stimulation of host plant defenses, or competitive colonization of spermosphere and rhizosphere substrates. However, soils are both densely populated and highly competitive habitats, and poor competitive ability of introduced fungal agents in soil communities, leading to unsuccessful establishment and activity, has often been observed [4].

Understanding effects of biodiversity on soil ecosystem functions requires integration both within trophic levels (i.e., horizontal diversity, the number of species within a trophic level) and across trophic levels (vertical diversity, 
the number of trophic levels) [5, 6]. The significance of both horizontal diversity and vertical diversity, from an agronomic perspective, may vary with the system being considered. A number of soilborne fungi (e.g., some members of the genera Fusarium, Rhizoctonia, Pythium, Sclerotinia, and others) are pathogenic on roots of both crop plants and weeds. Thus, they may be viewed either as harmful pathogens or as beneficial biocontrol agents, depending on the agronomic significance of the plant host. For example, Sclerotinia sclerotiorum and S. minor are important crop pathogens and also have been reported as weed biocontrol agents: $S$. sclerotiorum against knapweed [7] and S. minor against dandelion [8].

When analysis is limited only to host and parasite, the system may be horizontally diverse (several potential pathogens) but not vertically diverse (only two trophic levels: host and parasite). Studies of Sclerotinia as a weed biocontrol agent might typically be less vertically diverse (two trophic levels: host and parasite) compared to attempts at biological control of phytopathogenic Sclerotinia with a fungal hyperparasite such as Trichoderma (three trophic levels: crop plant, parasite, and biocontrol hyperparasite). Screening a large number of potential antagonists to a plant pathogen is an exercise that focuses exclusively on horizontal diversity. However, failure to account for nontrophic interactions and for trophic vertical diversity is likely one reason why promising potential biocontrol agents often fail to live up to expectations in the field. As one example, fluorescent pseudomonads and other bacteria have been shown to inhibit and lyse germlings of Trichoderma spp. [9]. We observed that a soil pseudomonad, Pseudomonas fluorescens isolate 2-79, significantly inhibited radial growth and hyphal density of the biocontrol fungus T. harzianum in soil [10]. In another study, we isolated a fungivorous nematode (Aphelenchoides sp.) from field soil and found that the nematode significantly reduced hyphal growth and total population of $T$. harzianum under soil environmental conditions favorable to nematode activity [11]. Because hyphal growth and proliferation are an attribute of the biocontrol fungus that appears to correlate with its success as a biocontrol agent, consideration of such nontrophic and vertically diverse trophic interactions may provide insight into the "failure parameters" that often plague biocontrol efforts.

Although numerous studies have suggested that, for effective biocontrol activity, successful hyphal growth and proliferation of the agent in soil or the rhizosphere are critical, the presence of an indigenous fungal microbiota makes this difficult to evaluate. As noted by Martin and English [12], the structural, physical, and biological complexity of the soil environment in which pathogens interact with plant roots constrain disease control options, including biological control. As seeds germinate and roots subsequently elongate, the spatial and temporal availability of infection courts are constantly changing. Colonization dynamics of biocontrol agents on seeds and roots, in the presence of an indigenous rhizosphere microbial community, will determine how well these potential infection courts are protected. One of the long-term goals of our research has been to understand and quantify some of the biotic and abiotic parameters that determine the establishment and activity of fungal agents introduced into natural habitats.

Certain organisms have received considerable research attention as potential biocontrol agents; one of the most well studied of these is the fungal genus Trichoderma. Trichoderma spp. have received considerable attention as potential biological control agents against a wide range of soilborne plant pathogenic fungi $[13,14]$. Members of the genus produce a number of fungal cell wall-degrading enzymes including chitinases, 1,3-glucanases, proteases, mannanases, and other hydrolases $[15,16]$. Trichoderma spp. are highly ecologically successful fungi and have been used increasingly in commercial agriculture, especially in the greenhouse industry where a significant proportion of soilborne disease control products are based on T. harzianum [15].

Isolates of Trichoderma harzianum have been reported as antagonists of several soilborne plant pathogens. An Idaho isolate of T. harzianum, ThzID1, controlled Fusarium wilt of Douglas-fir seedlings [17] and colonized sclerotia of Sclerotinia sclerotiorum under laboratory and field conditions $[10,18,19]$. Experimental biocontrol of the important pea pathogens Pythium ultimum and Aphanomyces euteiches f. sp. pisi has been obtained with agents including several bacterial species and also members of the genus Trichoderma $[9,18,20-24]$. Seed treatment of pea and other crops with $T$. harzianum controlled Pythium seed rot and/or preemergence damping-off [25-27].

Trichoderma spp. also have shown considerable potential for bioremediation activity in soil, especially for hydrocarbon pollutants, and many of the same ecological constraints on efficacy may apply in bioremediation systems. Trichoderma spp. and especially $T$. harzianum can degrade a number of soil pollutants; for example, Katayama and Matsumura [28] reported on the ability of $T$. harzianum to degrade organochlorine pesticides, particularly endosulfan. Ermisch and Rehm [29] described degradation of polycyclic aromatic hydrocarbons, including anthracene, by T. harzianum in soil. Because of the wealth of background information on Trichoderma spp. as both biocontrol and bioremediation agents, the genus is an excellent model for the investigation of factors influencing survival and proliferation of recombinant fungi introduced into the soil.

\section{Complex Soil Microbial Interactions: New Tools and Old Challenges}

2.1. Molecular and Microscopic Tools. Several factors constrain the observation, quantification, and evaluation of biocontrol fungi in soil. Although various methods have been used to study the occurrence and distribution of Trichoderma in natural soils [30-32], relatively few methods have allowed quantitative evaluation of population dynamics and proliferation. For example, in efforts to quantify the influence of temperature, soil matric potential, nutrient source, and antagonistic bacteria, on the hyphal growth and biocontrol efficacy of pelletized Trichoderma harzianum, it was not possible to differentiate the hyphal growth of this fungal agent from indigenous Trichoderma strains in natural soils [33, 34]. 
The use of dilution plating for numerical estimation of fungal population does not differentiate among the different propagules (hyphal fragments, conidia, and chlamydospores) that may generate colonies when plated on agar and thus is an unreliable estimate of fungal biomass and active physiological status [35]. The use of mutant strains resistant to specific fungicides may partially overcome problems related to nonspecific recovery [36], but this method does not allow for in situ monitoring of growth dynamics and survival structures of introduced Trichoderma strains or differentiation of introduced Trichoderma strains from indigenous strains.

More recently, genetic engineering of biocontrol agents with reporter or marker genes has provided useful tools for detection and monitoring of introduced biocontrol agents in natural environments [31,37]. The selectable hygromycin $\mathrm{B}(h y g B)$ phosphotransferase gene, encoding for resistance to this antibiotic, has been used to monitor survival of biocontrol agents in the rhizosphere or on the phylloplane $[37,38]$. The $\beta$-glucuronidase (GUS) reporter gene also is a promising tool for ecological studies of biocontrol agents [31]. Advantages of this reporter gene system include the low background activity of GUS in fungi and plants, the relative ease and sensitivity of detection [38], and the apparent lack of influence of GUS expression on biocontrol efficacy [39]. However, some GUS activity may be present in unsterile systems or natural soils. For example, Aspergillus niger has some indigenous GUS activity [39]. Therefore, for study of growth patterns of an introduced fungus in natural ecosystems, this reporter gene system may be less useful. The green fluorescent protein gene (GFP) of the jellyfish Aequorea victoria also has been developed as a reporter for gene expression [40]. Expression of cloned GFP has been reported in several organisms [41, 42]. GFP was shown to be a useful tool for studying host-fungal pathogen interactions in vivo [43] and has been used to assess colonization and dispersion of Aureobasidium pullulans in the phyllosphere [44]. GFP requires only UV or blue light and oxygen to induce green fluorescence. An exogenous substrate, which GUS requires, is not needed for the detection system to function, thus avoiding problems related to cell permeability and substrate uptake [42].

In our lab, we were able to use a stable transformant of T. harzianum expressing both GFP and GUS phenotypes [45] to evaluate aspects of the ecology of this organism in soil. The fungus was cotransformed with GFP, GUS, and hygromycin B (hygB) resistance, using PEG-mediated transformation. One cotransformant (strain ThzID1-M3) has been phenotypically stable with respect to GFP expression for several years, despite repeated subculturing without selection pressure. Morphology of ThzID1-M3 is similar to that of the wild-type strain. In nonsterile soil, growth, sporulation, and the ability of the cotransformant to colonize sclerotia of Sclerotinia sclerotiorum were compared with the wild-type strain. Wild-type and transformant strains both increased colonization of sclerotia above background levels of colonization by indigenous Trichoderma spp. in untreated controls. There were no significant differences in colonization levels between wild-type and cotransformant strains; however, presence of the GFP and GUS marker genes in the cotransformant strain allowed differentiation of introduced Trichoderma from indigenous strains. Formation of greenfluorescing conidiophores and conidia was observed within the first three days of incubation in soil, followed by formation of terminal and intercalary chlamydospores and subsequent disintegration of older hyphal segments. Addition of X-Gluc substrate to recovered glass slides confirmed the activity of GUS as well as GFP in the cotransformant in soil; the green color of cotransformant hyphae was clearly visible under UV epifluorescence, while indigenous fungi in the same samples were barely visible microscopically. In one study [11], interactions between ThzID1-M3 and the fungivorous nematode Aphelenchoides sp. were investigated in untreated field soil using epifluorescence microscopy; the GFP phenotype allowed for effective identification and quantification of hyphae of ThzID1-M3 in nonsterile soil. We have also used this method to evaluate effects of indigenous soil microflora on biomass and biocontrol efficacy of ThzID1-M3 in soil [46]. Combining epifluorescence with computer image analysis allowed quantification of mycelial biomass, over time, of the GFP-transformed ThzID1-M3 following its introduction into nonsterile soil [47].

Real-time PCR amplification of Trichoderma spp. gene sequences allowed quantification of sclerotia of S. sclerotiorum by Trichoderma spp. in nonsterile soil [48]. The fact that $T$. harzianum strain ThzID1-M3 is phenotypically different (in that it expresses GFP) from other soil fungi (including other Trichoderma strains) and that also the corresponding novel gene is well characterized provided another avenue of ecological investigation, since the GFP gene (which is of jellyfish origin) provided a unique sequence to design a polymerase chain reaction (PCR) primer/probe set to exclusively amplify that sequence from ThzID1-M3 [49]. We also compared quantitative real-time PCR with confocal microscopy to evaluate colonization of sclerotia by ThzID1-M3 and concluded that microscopy combined with image analysis provides better information on the spatial and temporal dynamics of sclerotial colonization, while real-time PCR can provide a more precise assessment of the total extent of colonization over time, including biomass estimates for the biocontrol fungus, and can more easily be used to sample entire sclerotia [50]. Real-time PCR primers were designed for the pea pathogen Fusarium solani f. sp. pisi, allowing for quantitative assessment of competitive interactions between the biocontrol fungus (T. harzianum ThzID1-M3) and the pathogen F. solani in the pea rhizosphere [51]. Thus, GFP activity of the transformant is a useful tool for nondestructive monitoring of hyphal proliferation and competitive ability of the fungus in a natural soil, and such transformants may provide useful models to investigate the ecological fitness of introduced fungi in soil.

Sometimes, scanning confocal laser microscopy (SLCM, or "confocal") can provide several advantages over conventional light or standard epifluorescence microscopy for visualization of microbes, such as those in colonized plant debris in soil or inside target pathogen structures (e.g., sclerotia). A confocal microscope combines fluorescence microscopy with electronic image analysis to obtain three-dimensional images. Confocal microscopy has proven to be a powerful 
tool for examining the structure, organization, and physiology of microbial cells on surfaces, among other uses [50, 52, 53]. The shallow depth of field (as little as $0.5-1.5 \mu \mathrm{m}$ ) of a confocal microscope allows information to be collected from well-defined optical sections rather than from most of the specimen as in conventional microscopy. Thus, out-of-focus fluorescence is eliminated, resulting in increased contrast and clarity. Effectively, the sample can be optically sectioned, and stacks of optical sections taken at successive focal planes (i.e., a "Z-series") can be reconstructed to produce a focused view of the sample.

2.2. Spatial Complexity of Soil Biocontrol Systems. Biological organisms and their controlling variables rarely are distributed in a random or in a uniform way, since the environment is spatially structured by various energy inputs that result in patchy structures or gradients [54]. The rhizoplane is a good example of this, since energy input is largely due to root exudates, and certain zones of roots produce more exudate than others [55]. Although only $1-2 \%$ of a root system may be colonized by microbes, space can be a limiting factor $[56,57]$. Sites may be preferentially colonized by some rhizoplane microbes and thus may no longer be available to others [58]. As a result, microbial distributions are not always random or uniform. The tendency for rhizosphere microbial population to conform to lognormal or similar frequency distributions has been noted [59-61], although there has been less attention to mechanisms of population development that might lead to such distributions.

Successful manipulation of rhizoplane microflora to enhance native or introduce beneficial microorganisms depends on knowledge of their ecological associations over time and space $[62,63]$. Mandeel and Baker [64] observed that potential infection courts on the rhizoplane can be protected by an agent that actively competes for these sites and that this mechanism has more potential impact on biocontrol efficiency than does rhizosphere nutrient competition. They suggested that efficiency values are influenced by spatial relationships, especially relative proximities of the pathogen to penetration sites compared to proximity of the biocontrol agent. We would further add that these spatial arrangements and their interactions evolve over time, so that understanding them is critical to effective biocontrol. Additionally, most previous work in this area has been done using gnotobiotic systems (e.g., [65-68]), so effects of the indigenous microbial community on the distributions of the pathogen and the inoculated biocontrol agent are not yet well understood.

Spatial variability of exudates from seeds and roots may influence sites of colonization of biocontrol agents as well as pathogens. Chemotaxis of zoospores and growth of mycelium towards roots are highly regulated by root exudates [6971]. Zoospores are an important infectious propagule for Pythium spp. The greatest accumulation of zoospores has been reported to be at approximately $2.5 \mathrm{~mm}$ behind the root tip (zone of cell elongation), where a major portion of diffusible compounds are exuded [71]. However, we found that Pythium ultimum var. sporangiiferum encysted throughout the root region and that the extent of zoospore aggregation was density dependent [66]. Pythium ultimum var. sporangiiferum represents a promising choice as a model organism to investigate spatial-temporal interactions between biocontrol agents and pathogens, since if access to spatially important entry sites for pathogens is blocked by biocontrol agents or other microbes, then infection and disease may be reduced. For example, Dandurand and Menge found that prior colonization of citrus roots by Fusarium solani reduced numbers of encysted zoospores of Phytophthora parasitica and $P$. citrophthora and reduced $P$. parasitica population $[70,72]$.

Deacon and Donaldson [73] described zoospores as "homing agents" or "site-selection agents", because their motility is linked to receptor functions for detecting environmental signals. They described the zoospore homing response as a sequence requiring two factors: a chemotactic stimulus and a suitable surface on which zoospores can orient [73]. Further, they pointed out that zoospores can precisely locate root tips, wounds, or even individual root cells, so that understanding the homing response and factors that may modify it is central to understanding zoosporic fungi and for attempts to control them. Spatial statistics may provide an effective tool for understanding this phenomenon and its ecological significance.

\subsection{Geostatistical Analysis as a Tool to Evaluate Spatial} Complexity. Nonpathogenic rhizoplane colonizers (biocontrol agents) at or near infection courts may be well positioned to modify the zoospore encystment process and subsequent root infection. For example, the frequency distribution of cucumber root sections without encysted zoospores of Pythium aphanidermatum was higher for roots treated with biocontrol bacteria than for untreated roots [74]. However, we suggest that frequency distribution analyses alone are not adequate to describe spatially structured biological phenomena [75-77], in part, because they assume independence of observations. The existence of spatial structure implies that the assumption of independence is not met, because any ecological phenomenon located at a given sampling point may have an influence on other points close by or some distance away [75].

What information can spatial statistics (e.g., geostatistics) provide that simple observation or distributional methods (e.g., frequency distributions and dispersion indices) do not? The variable success of biocontrol agents in controlling diseases may, in part, be caused by a lack of understanding of the spatial partitioning of resources in the rhizoplane. Spatial analysis of biocontrol agents may increase our predictive ability for effective biocontrol agents. For example, colonization patterns of bacteria were reported by Fukui et al. [20]; although it was observed that two strains colonized various parts of sugar beet seeds, a quantitative analysis of the spatial patterns of the two strains was not made, and conclusions derived from spatial patterns of the two bacteria based on observation only are difficult to interpret. A quantitative analysis of spatial patterns is particularly important to determine whether biocontrol agents change the spatial patterns of pathogens in predictable and consistent ways. Spatial statistical analysis provides a mechanism to explore 
processes that generate different patterns of organisms over time and helps to determine the sensitivity of spatial pattern to variations in these processes. Spatial analysis is defined here as any analysis that quantitatively evaluates variations or changes based on spatial orientation within a defined area or volume.

Frequency distribution methods are commonly based on mean/variance ratios, which do not provide reliable interpretations of spatial structure, since information on the location of each sample site is ignored. Although such indices are useful for estimation of population means, they do not maintain the spatial integrity of samples, making spatial analysis impossible [76-79]. Unlike frequency analysis, spatial analysis requires that the spatial integrity of observations be maintained; that is, spatial coordinates are recorded for each sample point. One method for spatial analysis, geostatistics, provides a quantitative assessment of spatial distributions that maintains the spatial integrity of data and is able to analyze the degree of association (autocorrelation) based on direction and distance between samples [80, 81]. Although geostatistics evolved primarily through mining applications, it has proven highly applicable to biological systems. For example, geostatistics has been used to evaluate insect spatial distributions [82, 83] and a spatial simulation model [77, 84], plant disease patterns $[76,85]$, and spatial patterns of zoospores and bacteria on roots $[66,67,86]$. Some advantages of geostatistics may be summarized as follows: geostatistics is independent of the relationship between the mean and variance; geostatistics maintains the spatial integrity of locations of samples and uses the variation between points to evaluate spatial dependence; geostatistics assesses spatial dependence quantitatively and can be used to compare spatial dependence at different points in time or at the same point in time under different conditions.

Although geostatistical analysis cannot say specifically what the mechanism of biocontrol activity of T. harzianum is, it can help give credence to hypotheses about mechanisms. As an example, Mandeel and Baker [64] observed that potential infection courts on the rhizoplane can be protected by an agent that actively competes for these sites, and they suggested that this mechanism has more potential impact on biocontrol efficiency than does rhizosphere nutrient competition. Mandeel and Baker further observed that biocontrol efficiency values are influenced by spatial relationships, especially relative proximities of the pathogen to penetration sites compared to proximity of the biocontrol agent [64]. If space is indeed a mechanism in biocontrol efficacy, then proliferation of the biocontrol agent would be expected to generate a change in observed spatial patterns of the pathogen population, as our preliminary results have indicated. However, these preliminary results were obtained in a gnotobiotic system. Of course, a recurring question in biological control research is why is biocontrol efficacy so variable in natural soils? Again, spatial statistical analysis can provide quantitative answers about whether spatial attributes of a biocontrol agent will change or not change in the presence of indigenous microbes. Effective development of spatially rigorous analysis techniques will provide a necessary framework for evaluating the effects of mechanisms that are studied at the genetic and biochemical level.

2.4. Simulation Modeling of Biocontrol Agent Performance. Fungi in soil perform beneficial roles that include biological control of soilborne plant pathogens. However, relatively little predictive information is available about the growth and activity of fungal hyphae in soil habitats. A number of fungal growth models deal primarily with aspects of physiology and morphogenesis (e.g., [87, 88]), and these may not be directly applicable to predict fungal proliferation in natural habitats; other models deal with colony pattern formation in $2 \mathrm{D}$ and 3D space. Knudsen \& Stack [89] introduced the idea of a simulation model for hyphal growth of a fungal hyperparasite through soil and use of the model to predict the incidence of hyperparasitism of sclerotia of certain soilborne plant pathogens. Lejeune and Baron [90] and Lejeune et al. [91] simulated the 3D growth of the filamentous fungus Trichoderma reesei, based on properties of mycelial growth (total hyphal length and total number of tips). Cross and Kenerley [92], using a combination of the Ratkowsky and Arrhenius equations, modeled colony growth of $T$. virens at different temperatures. Other models of fungal growth $[93,94]$ are useful for studying fungal physiology and morphogenesis but do not have an explicit spatial component (i.e., they assume spatial homogeneity) and thus may not be applicable to predict colony expansion in a heterogeneous environment.

Models developed for fungal growth in homogeneous environments, such as on agar surfaces or in culture media, may be less applicable to predict colony expansion in a heterogeneous environment. One potential way to deal with problems of spatial heterogeneity is the development of an "individual-based" model that tracks spatial attributes of the organism of interest as well as those of the local environment. With an individual-based model, information about individual organisms and/or habitat patches is retained in a database, and the model can then aggregate attributes of individuals to generate dynamics of the larger population. Thus, individualbased models represent an inductive approach to spatial population modeling in that population statistics are derived from collective attributes of individuals [95]. For example, we have used this approach to predict epizootics caused by the entomopathogen Beauveria bassiana in population of Russian wheat aphid on uniform versus nonuniform host plant distributions [77, 84].

There are important reasons why spatially homogeneous models of microbial growth kinetics and interactions are inadequate for some purposes, especially for analysis of mechanisms that generate different spatial dynamics as the population develops. If a biocontrol system is made more complex with patchily distributed agents and/or target pathogens, the spatial dimensions of the system become central to effective analysis and comprehensive understanding. Although description of spatially complex biological processes may sometimes most effectively be accomplished by modeling individuals, the concept of an "individual" is ambiguous for clonal organisms such as fungi. Numerically, physiologically, and often genetically, a single fungal colony 
is best described as a network of individual hyphal segments. Two advantages of this approach are as follows: first, the spatial structure of the fungal colony (hyphal network) can be explicitly reconstructed at any point in time; second, the approach has the flexibility to accommodate environments that are heterogeneous with respect to the spatial distribution of physical and biotic factors, and where phenotypic heterogeneity among individuals is present.

The objective of our "Fungmod" study [96] was to develop a modeling framework, in the form of an individual-based computer simulation model, that is suitable for exploration of the spatial dynamics of hyphal growth of a biocontrol fungus in a three-dimensional soil habitat. In that model, records of spatial location and branching hierarchy are maintained for individual hyphal nodes or for one or more fungal colonies. Thus, each hyphal segment is spatially referenced (coordinates in three dimensions) in terms of its ending node position, with its starting location referenced as the ending position of its parent node. In this way, the entire spatial structure of the fungal colony can be explicitly reconstructed from the data set at any point in time. The model proceeds at 1-day time steps and allows prediction of colony diameter, fungal biomass, and the spatial distribution of hyphae over time. The model was validated against data derived from image analysis of hyphal biomass accumulation in soil.

Although simulation models have been used extensively for arthropod biocontrol systems (e.g., [97]), relatively few models have been used for plant disease biocontrol studies. Knudsen and Hudler [98] described a simulation model to predict population dynamics of antibiotic-producing strains of Pseudomonas fluorescens on conifer foliage and subsequent effects on conidial germination of the fungal pathogen Gremmeniella abietina. Spurr and Knudsen [99] and Knudsen and Spurr [100] described how population models for antagonistic phylloplane bacteria might be incorporated into predictive models for foliar fungal diseases. However, those studies did not address spatial aspects of growth and proliferation of the putative control agents. For control of sclerotia-forming pathogens in soil, the ability of the biocontrol agent to effectively explore the threedimensional soil space via hyphal growth probably is more important than spatially localized proliferation, for example, via sporulation. During the initial stage of colony development in soil, hyphae of biocontrol fungi will obtain their energy from the formulation matrix and/or from substrata located within the soil volume in which they are growing. The extent of mycoparasitism thus would depend on the density and spatial arrangement both of target sclerotia and of hyphae of the biocontrol agent. Quantification of patterns and pattern changes in hyphal growth should enhance prediction of the likelihood of successful mycoparasitic events.

2.5. Trophic Complexity Influences the Success of Fungal Biocontrol Agents. A wide range of biotic factors, in addition to abiotic factors (e.g., [101]), influence growth and proliferation of fungi introduced into natural soils. However, there has been relatively little investigation of quantitative effects of the indigenous soil biota on growth and establishment of fungi introduced into natural soils as potential biocontrol agents. Especially, interactions between introduced fungi and soil microanimals have largely been neglected in studies relating to the potential proliferation and ecological impact of introduced fungal agents. Nematodes are the most abundant soilinhabiting animals; there are many described species (more than 80,000), and population densities typically are high in the top $5 \mathrm{~cm}$ of soils, with substantial seasonal differences in agricultural soils $[102,103]$. Identified nematode trophic groups include fungivores, bacterivores, omnivores, predators, and plant parasites [104]. Fungivorous nematodes have stylets and feed on mycelia of many different species of soil fungi, including beneficial fungi as well as plant pathogens [105].

Numerous species of fungivores have been found in soils [106]. The most common genera found in agricultural soils are Aphelenchoides, Aphelenchus, Tylenchus, and Ditylenchus $[106,107]$; some species within this group are plant parasites. Fungivores within this group of nematodes usually are found at lower densities than bacterivores or plant parasites [107]. However, if suitable fungi as food are available, population of fungivores may rapidly increase. Hofman and S'jacob [107] reported that numbers of the mycophagous nematodes Aphelenchoides sp., Aphelenchus avenae, and unidentified microbivorous nematodes increased severalfold within a few days on dying roots of flax that had been precolonized by $R h i-$ zoctonia solani. Many plant ectoparasitic nematodes also may be fungivorous, as the need arises [106]. For example, Ditylenchus destructor, which is parasitic on carrot, potato, alfalfa, radish, and sweet potato, also can be cultured on a variety of filamentous fungi [107].

Fungivorous nematodes may be a significant biotic constraint on activity of biocontrol fungi in the field, and experiments suggest that their presence introduces a layer of trophic complexity that needs to be factored into attempts to predict the fitness of introduced biocontrol fungi in soil. In our laboratory, we isolated a fungivorous nematode (Aphelenchoides sp.) from field soil and found that population of the nematode significantly reduced hyphal growth and total population of T. harzianum under some environmental conditions, in nonsterile field soil [11]. Addition of Aphelenchoides resulted in lower numbers of sclerotia colonized by T. harzianum compared to untreated controls [11]. Because the nematode feeds (via stylet) on hyphae of the fungus but is unable to feed on conidia or chlamydospores, active nematode population appears to have a disproportionate effect on fungal population that is actively growing (i.e., with a comparatively higher ratio of hyphae:spores) compared to population of Trichoderma that is primarily inactive. In a typical biocontrol scenario, the introduced fungus is applied to soil, often with a food base, from which it initiates hyphal growth (e.g., $[10,19,34])$. Meanwhile, the bulk of the indigenous Trichoderma population may be relatively inactive. Thus, if conditions are favorable for nematode activity, nematode feeding effectively will be selected against the introduced organism, and its apparent relative fitness compared to indigenous Trichoderma will be less. Perhaps ironically, soil environmental conditions that are favorable for nematode activity (adequate soil moisture and moderate 
temperature) are those that might otherwise be considered "ideal" for introduction of the fungal agent. The nematode $\mathrm{x}$ fungus interaction just described represents the first level of trophic complexity that may be a determinant of the (apparent) fitness of a recombinant fungus released into the environment.

Another aspect of trophic complexity may be implicated if hyphae of the biocontrol agent are able to contact and colonize the target substratum, that is, sclerotia of S. sclerotiorum, since colonized sclerotia potentially represent a refuge where the agent is protected from nematode activity and thus can persist. Similarly, because Trichoderma spp. are effective colonizers of plant debris, thecolonization of dead plant material may also provide a refuge from nematode activity. Refuge theory has played a prominent role in a large number of recent ecological studies, although to our knowledge it has not been addressed in microbial ecology. Hawkins et al. [108] applied principles of refuge theory to the biological control of insect pests using parasitoids and suggested that both theoretical and experimental results predict that success of biological control efforts (in insect pest/parasitoid systems) is inversely related to the proportion of insects protected from parasitoid attack. In general, parasitism rates increased as refuge level decreased [109]. However, it was also pointed out that research on refuge theory in entomology has largely been restricted to correlative studies and theory and that theoretical work has advanced more rapidly than experimental tests of the models' assumptions in part due to the difficulty of manipulating the feeding biology and refuges of individual insects in natural systems [109]. In the Aphelenchoides $x$ Trichoderma $x$ Sclerotinia system, however, the roles are quite different: one hypothesized refuge for $T$. harzianum is sclerotia of S. sclerotiorum, the target organism itself. Ability of the biocontrol agent to rapidly colonize this refuge may simultaneously effectuate biocontrol of the target sclerotia and also escape from feeding activity of fungivorous nematodes (however, recent experiments suggest that the nematode may also be able to enter sclerotia and feed there; R. Garcia De la Cruz \& G. R. Knudsen, unpublished). One aspect that these very different biological control systems (insect parasitoids and their hosts versus fungal hyperparasites and their hosts) have in common is, as described by Hawkins et al. [108], that refuges "...provide a general mechanism for interpreting ecological patterns at both the community level (their species diversity) and population level (their dynamics)." Again, it is anticipated that study of this phenomenon will be helpful in linking ecological theory with applied biotechnology risk assessment considerations.

\section{Conclusions}

As Spurr and Knudsen [99] noted, the search for a "silver bullet," a biological control organism that can simply be applied as if it were a chemical pesticide, is unlikely to succeed in an ecologically complex milieu. Ecological systems, as described by Levin [110], are the prototypical complex adaptive systems (CAS) "in which macroscopic system properties such as trophic structure, diversity-productivity relationships, and patterns of nutrient flux emerge from interactions among components, and may feed back to influence the subsequent development of those interactions." In recent years, the study of complex systems has contributed significantly to important research areas in ecology, namely, food (trophic) webs, patch dynamics and spatial structure, and population fluctuations [111-113]. We believe that each of these areas will continue to prove highly applicable and provide many research opportunities for biological control of soilborne plant pathogens.

\section{Conflict of Interests}

The research reported here was supported by the public sector, and the authors have no conflict of interests to report.

\section{References}

[1] V. Vasas and F. Jordán, "Topological keystone species in ecological interaction networks: considering link quality and nontrophic effects," Ecological Modelling, vol. 196, no. 3-4, pp. 365378, 2006.

[2] E. A. Herre, N. Knowlton, U. G. Mueller, and S. A. Rehner, "The evolution of mutualisms: exploring the paths between conflict and cooperation," Trends in Ecology and Evolution, vol. 14, no. 2, pp. 49-53, 1999.

[3] C. Neuhauser and J. E. Fargione, "A mutualism-parasitism continuum model and its application to plant-mycorrhizae interactions," Ecological Modelling, vol. 177, no. 3-4, pp. 337-352, 2004.

[4] J. A. van Veen, L. S. van Overbeek, and J. D. van Elsas, "Fate and activity of microorganisms introduced into soil," Microbiology and Molecular Biology Reviews, vol. 61, no. 2, pp. 121-135, 1997.

[5] J. E. Duffy, B. J. Cardinale, K. E. France, P. B. McIntyre, E. Thébault, and M. Loreau, "The functional role of biodiversity in ecosystems: incorporating trophic complexity, Ecology Letters, vol. 10, no. 6, pp. 522-538, 2007.

[6] D. S. Srivastava and T. Bell, "Reducing horizontal and vertical diversity in a foodweb triggers extinctions and impacts functions," Ecology Letters, vol. 12, no. 10, pp. 1016-1028, 2009.

[7] J. S. Jacobs, R. L. Sheley, and B. D. Maxwell, "Effect of Sclerotinia sclerotiorum on the interference between bluebunch wheatgrass (Agropyron spicatum) and spotted knapweed (Centaurea maculosa)," Weed Technology, vol. 10, no. 1, pp. 13-21, 1996.

[8] M. H. Abu-Dieyeh and A. K. Watson, "Efficacy of Sclerotinia minor for dandelion control: effect of dandelion accession, age and grass competition," Weed Research, vol. 47, no. 1, pp. 63-72, 2007.

[9] J. P. Hubbard, G. E. Harman, and Y. Hadar, "Effects of soilborne Pseudomonas spp. on the biological control agent, Trichoderma harzianum, on pea seeds," Phytopathology, vol. 73, pp. 655-659, 1983.

[10] L. Bin, G. R. Knudsen, and D. J. Eschen, "Influence of an antagonistic strain of Pseudomonas fluorescens on growth and ability of Trichoderma harzianum to colonize sclerotia of Sclerotinia sclerotiorum in soil," Phytopathology, vol. 81, pp. 994-1000, 1991.

[11] Y.-S. Bae and G. R. Knudsen, "Influence of a fungus-feeding nematode on growth and biocontrol efficacy of Trichoderma harzianum," Phytopathology, vol. 91, no. 3, pp. 301-306, 2001.

[12] F. N. Martin and J. T. English, "Population genetics of soilborne fungal plant pathogens," Phytopathology, vol. 87, no. 4, pp. 446447, 1997. 
[13] G. E. Harman, C. R. Howell, A. Viterbo, I. Chet, and M. Lorito, "Trichoderma species-opportunistic, avirulent plant symbionts," Nature Reviews Microbiology, vol. 2, no. 1, pp. 43-56, 2004.

[14] M. Vermaa, S. K. Brara, R. D. Tyagia, R. Y. Surampallib, and J. R. Valéroa, "Antagonistic fungi, Trichoderma spp.: panoply of biological control," Biochemical Engineering Journal, vol. 37, no. 1, pp. 1-20, 2007.

[15] G. E. Harman, "Myths and dogmas of biocontrol: changes in perceptions derived from research on Trichoderma harzianum T-22," Plant Disease, vol. 84, no. 4, pp. 377-393, 2000.

[16] M. C. Limón, M. R. Chacón, R. Mejías et al., "Increased antifungal and chitinase specific activities of Trichoderma harzianum CECT 2413 by addition of a cellulose binding domain," Applied Microbiology and Biotechnology, vol. 64, no. 5, pp. 675-685, 2004.

[17] M. R. Mousseaux, R. K. Dumroese, R. L. James, D. L. Wenny, and G. R. Knudsen, "Efficacy of Trichoderma harzianum as a biological control of Fusarium oxysporum in container-grown Douglas-fir seedlings," New Forests, vol. 15, no. 1, pp. 11-21, 1998.

[18] L.-M. Dandurand, R. D. Mosher, and G. R. Knudsen, "Combined effects of Brassica napus seed meal and Trichoderma harzianum on two soilborne plant pathogens," Canadian Journal of Microbiology, vol. 46, no. 11, pp. 1051-1057, 2000.

[19] G. R. Knudsen, D. J. Eschen, L. M. Dandurand, and L. Bin, "Potential for control of Sclerotinia sclerotiorum through colonization of sclerotia by Trichoderma harzianum," Plant Disease, vol. 75, pp. 466-470, 1991.

[20] R. Fukui, E. I. Poinar, P. H. Bauer et al., "Spatial colonization patterns and interaction of bacteria on inoculated sugar beet seed," Phytopathology, vol. 84, no. 11, pp. 1338-1345, 1994.

[21] G. E. Harman, R. Petzoldt, A. Comis, and J. Chen, "Interactions between Trichoderma harzianum strain T22 and maize inbred line Mol7 and effects of these interactions on diseases caused by Pythiuin ultimum and Colletotrichum graminicola," Phytopathology, vol. 94, no. 2, pp. 147-153, 2004.

[22] W. Mao, R. D. Lumsden, J. A. Lewis, and P. K. Hebbar, "Seed treatment using pre-infiltration and biocontrol agents to reduce damping-off of corn caused by species of Pythium and Fusarium," Plant Disease, vol. 82, no. 3, pp. 294-299, 1998.

[23] A. Muthukumar, A. Eswaran, S. Nakkeeran, and G. Sangeetha, "Efficacy of plant extracts and biocontrol agents against Pythium aphanidermatum inciting chilli damping-off," Crop Protection, vol. 29, no. 12, pp. 1483-1488, 2010.

[24] T. C. Paulitz, "Effect of Pseudomonas putida on the stimulation of Pythium ultimum by seed volatiles of pea and soybean," Phytopathology, vol. 81, pp. 1282-1287, 1991.

[25] G. E. Harman, "Myths and dogmas of biocontrol: changes in perceptions derived from research on Trichoderma harzianum T-22," Plant Disease, vol. 84, no. 4, pp. 377-393, 2000.

[26] N. Benhamou and I. Chet, "Cellular and molecular mechanisms involved in the interaction between Trichoderma harzianum and Pythium ultimum," Applied and Environmental Microbiology, vol. 63, pp. 2095-2099, 1997.

[27] C. R. Howell, "Mechanisms employed by Trichoderma species in the biological control of plant diseases: the history and evolution of current concepts," Plant Disease, vol. 87, no. 1, pp. 4-10, 2003.

[28] A. Katayama and F. Matsumura, "Degradation of organochlorine pesticides, particularly endosulfan, by Trichoderma harzianum," Environmental Toxicology and Chemistry, vol. 12, no. 6, pp. 1059-1065, 1993.
[29] O. Ermisch and H. J. Rehm, "Degradation of polycyclic aromatic hydrocarbons by the immobilized mold Trichoderma harzianum in soil," in Proceedings of the DECHEMA Annual Meeting on Biotechnology and 58th Meeting of the European Biotechnology Federations, and Joint Meeting of Society for Industry Microbiology (SIM '89), pp. 780-781, 1989.

[30] I. Grishkan, E. Nevo, S. P. Wasser, and A. Beharav, "Adaptive spatiotemporal distribution of soil microfungi in "Evolution Canyon" II, Lower Nahal Keziv, western Upper Galilee, Israel," Biological Journal of the Linnean Society, vol. 78, no. 4, pp. 527539, 2003.

[31] H. Green and D. F. Jensen, "A tool for monitoring Trichoderma harzianum: II. The use of a GUS transformant for ecological studies in the rhizosphere," Phytopathology, vol. 85, no. 11, pp. 1436-1440, 1995.

[32] C.-L. Zhang, I. S. Druzhinina, C. P. Kubicek, and T. Xu, "Trichoderma biodiversity in China: evidence for a North to South distribution of species in East Asia," FEMS Microbiology Letters, vol. 251, no. 2, pp. 251-257, 2005.

[33] G. R. Knudsen and L. Bin, "Effects of temperature, soil moisture and wheat bran on growth of Trichoderma harzianum from alginate pellets," Phytopathology, vol. 80, pp. 724-727, 1990.

[34] G. R. Knudsen, D. J. Eschen, L. M. Dandurand, and Z. G. Wang, "Method to enhance growth and sporulation of pelletized biocontrol fungi," Applied and Environmental Microbiology, vol. 57, no. 10, pp. 2864-2867, 1991.

[35] R. D. Lumsden, J. P. Carter, J. M. Whipps, and J. M. Lynch, "Comparison of biomass and viable propagule measurements in the antagonism of Trichoderma harzianum against Pythium ultimum," Soil Biology and Biochemistry, vol. 22, no. 2, pp. 187194, 1990.

[36] J. Rigot and F. Matsumura, "Assessment of the rhizosphere competency and pentachlorophenol-metabolizing activity of a pesticide-degrading strain of Trichoderma harzianum introduced into the root zone of corn seedlings," Journal of Environmental Science and Health B: Pesticides, Food Contaminants, and Agricultural Wastes, vol. 37, no. 3, pp. 201-210, 2002.

[37] C.-T. Lo, E. B. Nelson, C. K. Hayes, and G. E. Harman, "Ecological studies of transformed Trichoderma harzianum strain 1295-22 in the rhizosphere and on the phylloplane of creeping bentgrass," Phytopathology, vol. 88, no. 2, pp. 129-136, 1998.

[38] I. N. Roberts, R. P. Oliver, P. J. Punt, and C. A. M. J. J. Van den Hondel, "Expression of the Escherichia coli $\beta$-glucuronidase gene in industrial and phytopathogenic filamentous fungi," Current Genetics, vol. 15, no. 3, pp. 177-180, 1989.

[39] C. Thrane, M. Lubeck, H. Green et al., "A tool for monitoring Trichoderma harzianum: I. Transformation with the GUS gene by protoplast technology," Phytopathology, vol. 85, no. 11, pp. 1428-1435, 1995.

[40] M. Chalfie, Y. Tu, G. Euskirchen, W. W. Ward, and D. C. Prasher, "Green fluorescent protein as a marker for gene expression," Science, vol. 263, no. 5148, pp. 802-805, 1994.

[41] B. P. Cormack, G. Bertram, M. Egerton, N. A. R. Gow, S. Falkow, and A. J. P. Brown, "Yeast-enhanced green fluorescent protein (yGFP): a reporter of gene expression in Candida albicans," Microbiology, vol. 143, no. 2, pp. 303-311, 1997.

[42] J. Sheen, H. S. Hwang Seongbin, Y. Niwa, H. Kobayashi, and D. W. Galbraith, "Green-fluorescent protein as a new vital marker in plant cells," Plant Journal, vol. 8, no. 5, pp. 777-784, 1995.

[43] T. Spellig, A. Bottin, and R. Kahmann, "Green fluorescent protein (GFP) as a new vital marker in the phytopathogenic 
fungus Ustilago maydis," Molecular and General Genetics, vol. 252, no. 5, pp. 503-509, 1996.

[44] A. J. Vanden Wymelenberg, D. Cullen, R. N. Spear, B. Schoenike, and J. H. Andrews, "Expression of green fluorescent protein in Aureobasidium pullulans and quantification of the fungus on leaf surfaces," Bioechniques, vol. 23, no. 4, pp. 686690, 1997.

[45] Y. S. Bae and G. R. Knudsen, "Cotransformation of Trichoderma harzianum with $\beta$-glucuronidase and green fluorescent protein genes provides a useful tool for monitoring fungal growth and activity in natural soils," Applied and Environmental Microbiology, vol. 66, no. 2, pp. 810-815, 2000.

[46] Y. S. Bae and G. R. Knudsen, "Soil microbial biomass influence on growth and biocontrol efficacy of Trichoderma harzianum," Biological Control, vol. 32, no. 2, pp. 236-242, 2005.

[47] K. A. Orr and G. R. Knudsen, "Use of green fluorescent protein and image analysis to quantify proliferation of Trichoderma harzianum in nonsterile soil," Phytopathology, vol. 94, no. 12, pp. 1383-1389, 2004.

[48] T. G. Kim and G. R. Knudsen, "Quantitative real-time PCR effectively detects and quantifies colonization of sclerotia of Sclerotinia sclerotiorum by Trichoderma spp," Applied Soil Ecology, vol. 40, no. 1, pp. 100-108, 2008.

[49] T. G. Kim and G. R. Knudsen, "Colonization of Sclerotinia sclerotiorum sclerotia by a biocontrol isolate of Trichoderma harzianum, and effects on myceliogenic germination," Biocontrol Science and Technology, vol. 19, no. 10, pp. 1081-1085, 2009.

[50] T. G. Kim and G. R. Knudsen, "Comparison of real-time PCR and microscopy to evaluate sclerotial colonisation by a biocontrol fungus," Fungal Biology, vol. 115, no. 4-5, pp. 317-325, 2011.

[51] T. G. Kim and G. R. Knudsen, "Relationship between the biocontrol fungus Trichoderma harzianum and the phytopathogenic fungus Fusarium solani f.sp. pisi," Applied Soil Ecology, vol. 68, pp. 57-60, 2013.

[52] C.-T. Huang, F. P. Yu, G. A. McFeters, and P. S. Stewart, "Nonuniform spatial patterns of respiratory activity within biofilms during disinfection," Applied and Environmental Microbiology, vol. 61, no. 6, pp. 2252-2256, 1995.

[53] J. S. McLean, O. N. Ona, and P. D. Majors, "Correlated biofilm imaging, transport and metabolism measurements via combined nuclear magnetic resonance and confocal microscopy," ISME Journal, vol. 2, no. 2, pp. 121-131, 2008.

[54] P. Legendre and M. J. Fortin, "Spatial pattern and ecological analysis," Vegetatio, vol. 80, no. 2, pp. 107-138, 1989.

[55] A. D. Rovira, "Zones of exudation along plant roots and spatial distribution of microoorganisms in the rhizosphere," Pesticide Science, vol. 4, no. 3, pp. 361-366, 1973.

[56] S. Compant, C. Clément, and A. Sessitsch, "Plant growthpromoting bacteria in the rhizo- and endosphere of plants: their role, colonization, mechanisms involved and prospects for utilization," Soil Biology and Biochemistry, vol. 42, no. 5, pp. 669-678, 2010.

[57] A. Ramette and J. M. Tiedje, "Multiscale responses of microbial life to spatial distance and environmental heterogeneity in a patchy ecosystem," Proceedings of the National Academy of Sciences of the United States of America, vol. 104, no. 8, pp. 27612766, 2007.

[58] A. J. H. Davey, C. P. Doncaster, and O. D. Jones, "Distinguishing between interference and exploitation competition for shelter in a mobile fish population," Environmental Modeling and Assessment, vol. 14, no. 5, pp. 555-562, 2009.
[59] E. Limpert, W. A. Stahel, and M. Abbt, "Log-normal distributions across the sciences: keys and clues," BioScience, vol. 51, no. 5, pp. 341-352, 2001.

[60] J. E. Loper, T. V. Suslow, and M. N. Schroth, "Lognormal distribution of bacterial populations in the rhizosphere," Phytopathology, vol. 74, pp. 1454-1460, 1984.

[61] G. Wieland, R. Neumann, and H. Backhaus, "Variation of microbial communities in soil, rhizosphere, and rhizoplane in response to crop species, soil type, and crop development," Applied and Environmental Microbiology, vol. 67, no. 12, pp. 5849-5854, 2001.

[62] J. M. Raaijmakers, T. C. Paulitz, C. Steinberg, C. Alabouvette, and Y. Moënne-Loccoz, "The rhizosphere: a playground and battlefield for soilborne pathogens and beneficial microorganisms," Plant and Soil, vol. 321, no. 1-2, pp. 341-361, 2009.

[63] M. E. Stanghellini and S. L. Rasmussen, "Root prints: a technique for the determination of the in situ spatial distribution of bacteria on the rhizoplane of field-grown plants," Phytopathology, vol. 79, pp. 1131-1134, 1989.

[64] Q. Mandeel and R. Baker, "Mechanisms involved in biological control of Fusarium wilt on cucumber with strains of nonpathogenic Fusarium oxysporum," Phytopathology, vol. 81, pp. 462-469, 1991.

[65] T. F. C. Chin A Woeng, W. de Priester, A. J. van der Bij, and B. J. Lugtenberg, "Description of the colonization of a gnotobiotic tomato rhizosphere by Pseudomonas fluorescens biocontrol strain WCS365, using scanning electron microscopy," Molecular Plant Microbe Interactions, vol. 10, no. 1, pp. 79-86, 1997.

[66] L. M. Dandurand, G. R. Knudsen, and D. J. Schotzko, "Quantification of Pythium ultimum var. sporangiiferum zoospore encystment patterns using geostatistics," Phytopathology, vol. 85, no. 2, pp. 186-190, 1995.

[67] L. M. Dandurand, D. J. Schotzko, and G. R. Knudsen, "Spatial patterns of rhizoplane populations of Pseudomonas fluorescens," Applied and Environmental Microbiology, vol. 63, pp. 3211-3217, 1997.

[68] M. Simons, A. J. van der Bij, I. Brand, L. A. de Weger, C. A. Wijffelman, and B. J. J. Lugtenberg, "Gnotobiotic system for studying rhizosphere colonization by plant growth-promoting Pseudomonas bacteria," Molecular Plant Microbe Interactions, vol. 9, pp. 600-607, 1996.

[69] C. A. Walker and P. van West, "Zoospore development in the oomycetes," Fungal Biology Reviews, vol. 21, no. 1, pp. 10-18, 2007.

[70] L. M. Dandurand and J. A. Menge, "Influence of Fusarium solani on chemotaxis of zoospores of Phytophthora parasitica and Phytophthora citrophthora and on distribution of $14 \mathrm{C}$ in citrus tissues and root exudate," Soil Biology and Biochemistry, vol. 26, no. 1, pp. 75-79, 1994.

[71] R. T. Mitchell and J. W. Deacon, "Differential (host-specific) accumulation of zoospores of Pythium on roots of graminaceous and non-graminaceous plants," New Phytologist, vol. 102, pp. 113-122, 1986.

[72] L. M. Dandurand and J. A. Menge, "Influence of Fusarium solani on citrus root rot caused by Phytophthora parasitica and Phytophthora citrophthora," Plant and Soil, vol. 144, no. 1, pp. 1321, 1992.

[73] J. W. Deacon and S. P. Donaldson, "Molecular recognition in the homing responses of zoosporic fungi, with special reference to Pythium and Phytophthora," Mycological Research, vol. 97, no. 10, pp. 1153-1171, 1993. 
[74] T. Zhou and T. C. Paulitz, "In vitro and in vivo effects of Pseudomonas spp. on Pythium aphanidermatum: zoospore behavior in exudates and on the rhizoplane of bacteria-treated cucumber roots," Phytopathology, vol. 83, pp. 872-876, 1993.

[75] P. Legendre, "Spatial autocorrelation: trouble or new paradigm?” Ecology, vol. 74, no. 6, pp. 1659-1673, 1993.

[76] P. C. Nicot, D. I. Rouse, and B. S. Yandell, "Comparison of statistical methods for studying spatial patterns of soilborne plant pathogens in the field," Phytopathology, vol. 74, pp. 13991402, 1984.

[77] D. J. Schotzko and G. R. Knudsen, "Use of geostatistics to evaluate a spatial simulation of Russian wheat aphid (Homoptera: Aphididae) movement behavior on preferred and nonpreferred hosts," Environmental Entomology, vol. 21, no. 6, pp. 1271-1282, 1992.

[78] P. A. Jumars, D. Thistle, and M. L. Jones, "Detecting twodimensional spatial structure in biological data," Oecologia, vol. 28, no. 2, pp. 109-123, 1977.

[79] A. J. Sawyer, "Inconstancy of Taylor's b: simulated sampling with different quadrat sizes and spatial distributions," Researches on Population Ecology, vol. 31, no. 1, pp. 11-24, 1989.

[80] E. H. Isaaks and R. H. Srivastava, Applied Geostatistics, Oxford University Press, Oxford, UK, 1989.

[81] B. B. Trangmar, R. S. Yost, and G. Uehara, "Application of geostatistics to spatial studies of soil properties," Advances in Agronomy, vol. 38, pp. 45-94, 1985.

[82] W. P. Kemp, T. M. Kalaris, and W. F. Quimby, "Rangeland grasshopper (Orthoptera: Acrididae) spatial variability: macroscale population assessment," Journal of Economic Entomology, vol. 82, pp. 1270-1276, 1989.

[83] D. J. Schotzko and C. M. Smith, "Effect of host plant on the plant to plant distribution of the Russian wheat aphid (Homoptera: Aphididae)," Journal of Economic Entomology, vol. 84, pp. 1725$1734,1991$.

[84] G. R. Knudsen and D. J. Schotzko, "Spatial simulation of epizootics caused by Beauveria bassiana in Russian wheat aphid populations," Biological Control, vol. 16, no. 3, pp. 318-326, 1999.

[85] D. A. Johnson, J. R. Alldredge, J. R. Allen, and R. Allwine, "Spatial pattern of downy mildew in hop yards during severe and mild diesease epidemics," Phytopathology, vol. 81, pp. 13691374, 1991.

[86] G. R. Knudsen and L. M. Dandurand, "Analysis of spatial patterns of rhizoplane colonization," in The Spatial Distribution of Microbes in the Environment, R. B. Franklin and A. L. Mills, Eds., pp. 109-133, Springer, New York, NY, USA, 2007.

[87] L. Edelstein, "The propagation of fungal colonies: a model for tissue growth," Journal of Theoretical Biology, vol. 98, no. 4, pp. 679-701, 1982.

[88] L. Edelstein, Y. Hadar, and I. Chet, "A model for fungal colony growth applied to Sclerotium rolfsii," Journal of General Microbiology, vol. 129, no. 6, pp. 1873-1881, 1983.

[89] G. R. Knudsen and J. P. Stack, "Modeling growth and dispersal of fungi in natural environments," in Handbook of Applied Mycology, Vol. I: Soil and Plants, D. K. Arora, K. G. Mukerji, B. Rai, and G. R. Knudsen, Eds., pp. 625-645, Marcel Dekker, New York, NY, USA, 1991.

[90] R. Lejeune and G. V. Baron, "Simulation of growth of a flamentous fungus in 3 dimensions," Biotechnology and Bioengineering, vol. 53, no. 2, pp. 139-150, 1997.

[91] R. Lejeune, J. Nielsen, and G. V. Baron, "Morphology of Trichoderma reesei QM 9414 in submerged cultures," Biotechnology and Bioengineering, vol. 47, no. 5, pp. 609-615, 1995.
[92] D. Cross and C. M. Kenerley, "Modelling the growth of Trichoderma virens with limited sampling of digital images," Journal of Applied Microbiology, vol. 97, no. 3, pp. 486-494, 2004.

[93] A. P. J. Trinci, "Regulation of hyphal branching and hyphal orientation," in The Ecology and Physiology of Fungal Mycelium, D. H. Jennings and A. D. M. Rayner, Eds., pp. 23-52, Cambridge University Press, Cambridge, UK, 1984.

[94] J. G. H. Wessels, "A steady-state model for apical wall growth in fungi," Acta Botanica Neerlandica, vol. 37, pp. 3-16, 1988.

[95] M. Huston, D. DeAngelis, and W. Post, "New computer models unify ecological theory," BioScience, vol. 38, pp. 682-691, 1988.

[96] G. R. Knudsen, J. P. Stack, S. O. Schuhmann, K. Orr, and C. LaPaglia, "Individual-based approach to modeling hyphal growth of a biocontrol fungus in soil," Phytopathology, vol. 96, no. 10, pp. 1108-1115, 2006.

[97] A. A. de Souza, S. G. F. Martins, and M. S. Zacarias, "Computer simulation applied to the biological control of the insect Aphis gossypii for the parasitoid Lysiphlebus testaceipes," Ecological Modelling, vol. 220, no. 6, pp. 756-763, 2009.

[98] G. R. Knudsen and G. W. Hudler, "Use of a computer simulation model to evaluate a plant disease biocontrol agent," Ecological Modelling, vol. 35, no. 1-2, pp. 45-62, 1987.

[99] H. W. Spurr Jr. and G. R. Knudsen, "Biological control of leaf diseases with bacteria," in Biological Control on the Phylloplane, C. E. Windels and S. E. Lindow, Eds., pp. 45-62, American Phytopathological Society, St. Paul, Minn, USA, 1985.

[100] G. R. Knudsen and H. W. Spurr Jr., "Field persistence and efficacy of five bacterial preparations for control of peanut leaf spot," Plant Disease, vol. 71, no. 5, pp. 442-445, 1987.

[101] B. K. Duffy, B. H. Ownley, and D. M. Weller, "Soil chemical and physical properties associated with suppression of take-all of wheat by Trichoderma koningii," Phytopathology, vol. 87, no. 11, pp. 1118-1124, 1997.

[102] E. A. Paul and F. E. Clark, "Components of the soil biota," in Soil Microbiology and Biochemistry, pp. 69-107, Academic Press, New York, NY, USA, 2nd edition, 1996.

[103] G. W. Yeates, D. A. Wardle, and R. N. Watson, "Responses of soil nematode populations, community structure, diversity and temporal variability to agricultural intensification over a sevenyear period," Soil Biology and Biochemistry, vol. 31, no. 12, pp. 1721-1733, 1999.

[104] W. L. Nicholas, The Biology of Free-Living Nematodes, Clarendon, Oxford, UK, 2nd edition, 1984.

[105] G. L. Barnes, C. C. Russell, W. D. Foster, and R. W. McNew, "Aphelenchus avenae, a potential biological control agent for root rot fungi," Plant Disease, vol. 65, pp. 423-424, 1981.

[106] D. W. Freckman and E. P. Caswell, "The ecology of nematodes in agroecosystems," Annual Review of Phytopathology, vol. 23, pp. 275-296, 1985.

[107] T. W. Hofman and J. J. S'jacob, "Distribution and dynamics of mycophagous and microbivorous nematodes in potato fields and their relationship to some food sources," Annals of Applied Biology, vol. 115, no. 2, pp. 291-298, 1989.

[108] B. A. Hawkins, M. B. Thomas, and M. E. Hochberg, "Refuge theory and biological control," Science, vol. 262, no. 5138, pp. 1429-1432, 1993.

[109] E. E. Porter and B. A. Hawkins, "Coexistence of specialist parasitoids with host refuges in the laboratory and the dynamics of spatial heterogeneity in attack rate," Oikos, vol. 100, no. 2, pp. 232-240, 2003. 
[110] S. A. Levin, "Ecosystems and the biosphere as complex adaptive systems," Ecosystems, vol. 1, no. 5, pp. 431-436, 1998.

[111] M. Anand, A. Gonzalez, F. Guichard, J. Kolasa, and L. Parrott, "Ecological systems as complex systems: challenges for an emerging science," Diversity, vol. 2, no. 3, pp. 395-410, 2010.

[112] J. Jabiol, B. G. McKie, A. Bruder, C. Bernadet, M. O. Gessner, and E. Chauvet, "Trophic complexity enhances ecosystem functioning in an aquatic detritus-based model system," Journal of Animal Ecology, vol. 82, no. 5, pp. 1042-1051, 2013.

[113] R. E. Ulanowicz, R. D. Holt, and M. Barfield, "Limits on ecosystem trophic complexity: insights from ecological network analysis," Ecology Letters, vol. 17, no. 2, pp. 127-136, 2014. 


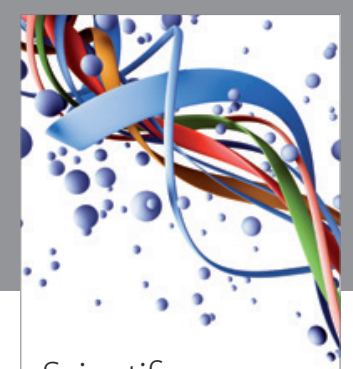

Scientifica
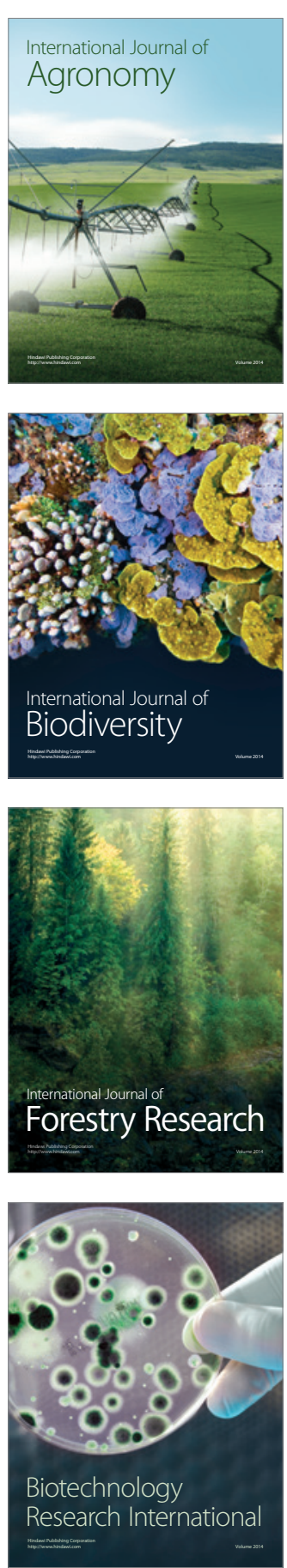
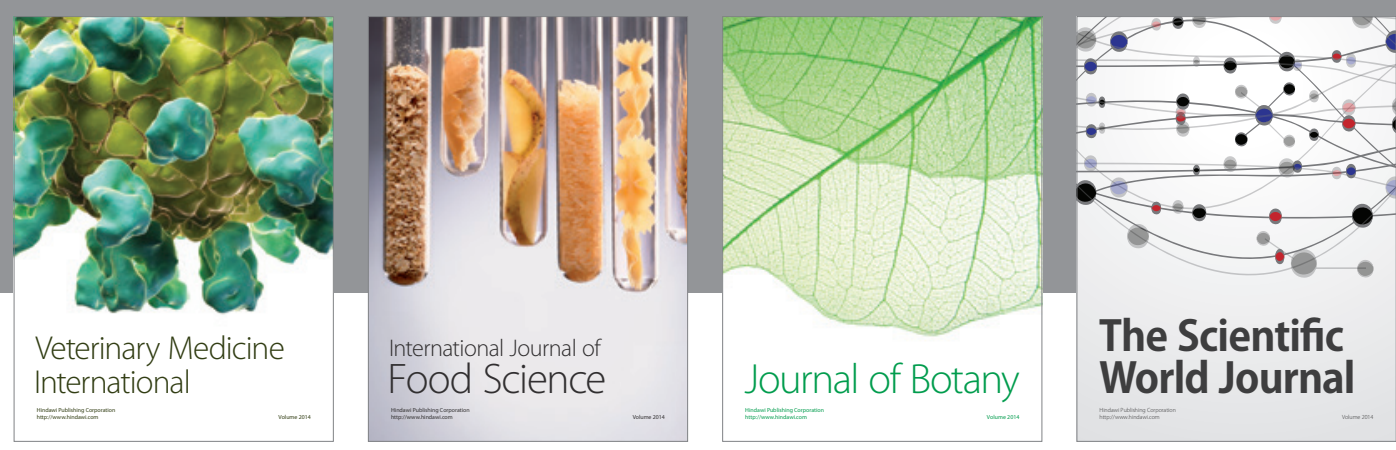

The Scientific World Journal
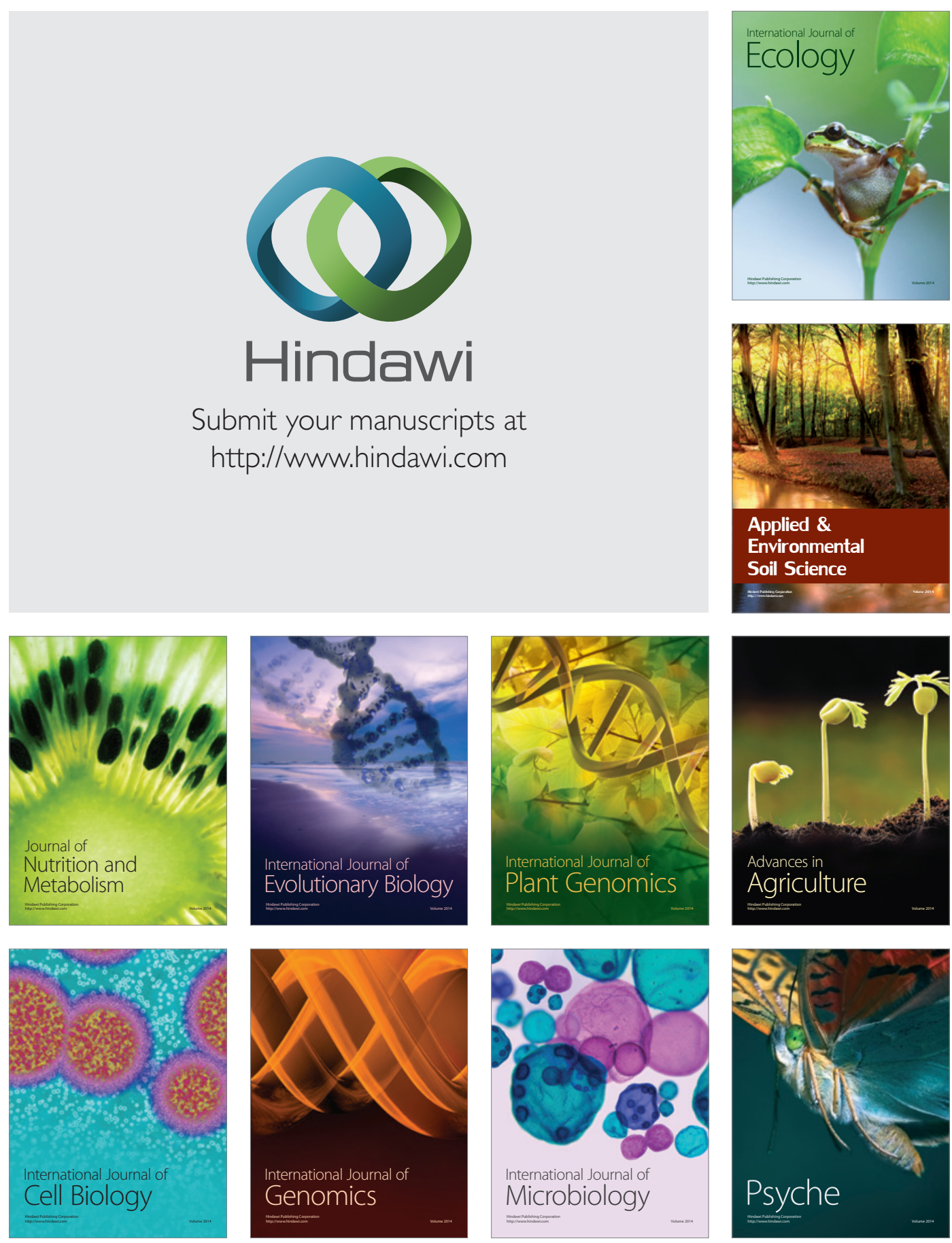